\title{
An Efficient Estimation Method Based on Double Phase Sampling
}

\author{
Amjad D. Al-Nasser and Mohammed Al-Haj Ebrahem \\ Yarmouk University, Irbid, Jordan
}

\begin{abstract}
In this paper an estimation method based on double phase sampling is proposed to improve the efficiency of estimating the population mean. An extension is presented for the bivariate case to estimate the parameters of the simple linear regression model. Conclusions of this study show that using the proposed method with symmetric populations, the estimator of the population mean is unbiased and more efficient than the traditional one that is based on a simple random sample. Results for the standard uniform and the exponential distribution are given. Simulation results show that the proposed method is also more efficient than the traditional one in case of estimating the regression parameters. An application to a real data set is also given.
\end{abstract}

Zusammenfassung: In dieser Arbeit wird eine Schätzmethode basierend auf ein Double Phase Sampling vorgeschlagen, um die Effizienz der Schätzung des Populationsmittels zu steigern. Eine Erweiterung auf den bivariaten Fall wird präsentiert, um die Parameter eines einfachen linearen Regressionsmodells zu schätzen. Die Ergebnisse dieser Studie zeigen, dass die vorgeschlagene Methode bei symmetrischen Populationen einen unverzerrten Schätzer für das Populationsmittel liefert, der auch effizienter ist als der traditionelle basierend auf einer einfachen Zufallsstichprobe. Resultate für die StandardUniformverteilung und die Exponentialverteilung werden angegeben. Simulationsergebnisse zeigen, dass diese Methode auch bei der Schätzung der Regressionsparameter effizienter ist als die traditionelle. Eine Anwendung auf reale Daten ist auch enthalten.

Keywords: Simple Linear Regression, Least Squares Estimator, Efficiency.

\section{Introduction}

Numerous procedures have been proposed for increasing the precision of parameters estimation. One of such procedures is to use a double phase sampling theory which has been around for a long time (Deming, 1953). In this paper, we propose a modified Theil's type nonparametric method that is based on a double phase sampling, to estimate the population mean and the parameters of the simple linear regression model. The proposed method is an extension of the simple AM sampling procedure that was introduced by the authors of this paper (Al-Nasser and Al-Haj Ebrahem, 2005; Al-Haj Ebrahem and Al-Nasser, 2005). The simple AM method can be described as follows:

1. Arrange the observations in ascending order on the basis of the values of the $x_{i}$ 's, i.e. $x_{(1: n)} \leq x_{(2: n)} \leq \cdots \leq x_{(n: n)}$ and the associated $y_{[1]}, y_{[2]}, \ldots, y_{[n]}$ of the original data are taken. Thus the new pairs will be $\left(x_{(i: n)}, y_{[i]}\right), i=1, \ldots, n$. Note that $x_{(i: n)}$ is the $i$-th ordered observation from a sample of size $n$. 
2. Divide the ordered data into $m$-subgroups each of size $r$, such that $m r=n$. The sample can be rewritten as

$$
\begin{array}{cccc}
\left(x_{(1: n)}, y_{[1]}\right) & \left(x_{(2: n)}, y_{[2]}\right) & \cdots & \left(x_{(r: n)}, y_{[r]}\right) \\
\left(x_{(r+1: n)}, y_{[r+1]}\right) & \left(x_{(r+2: n)}, y_{[r+2]}\right) & \cdots & \left(x_{(2 r: n)}, y_{[2 r]}\right) \\
\vdots & \vdots & \cdots & \vdots \\
\left(x_{(((m-1) r+1): n)}, y_{[(m-1) r+1]}\right) & \left(x_{(((m-1) r+2): n)}, y_{[(m-1) r+2]}\right) & \cdots & \left(x_{(m r: n)}, y_{[m r]}\right) .
\end{array}
$$

Note that $m$ can be chosen to be the maximum divisor of $n$ such that $m \leq r$.

3. Find all possible paired slopes

$$
\left\{b(k)_{i j}=\frac{y_{[j]}-y_{[i]}}{x_{(j: n)}-x_{(i: n)}}, i=1, \ldots, j-1, j=2, \ldots, r\right\}, k=1, \ldots, m .
$$

4. The estimator of the slope can be defined as

$$
\text { Slope estimate }=\operatorname{Median}_{k}\left\{b(k)_{i j}\right\} .
$$

Based on a simulation study, the authors had demonstrated that the simple AM method could be considered as a good alternative to the traditional methods, because it was able to produce satisfactory results.

The paper is organized as follows. Estimation of the population mean using an extension of the AM method and results from the standard uniform distribution and exponential distribution are presented in Section 2. The proposed sampling plan to estimate the regression coefficients is described in Section 3. Application to a real data set is given in Section 4. Simulation study and conclusions are discussed in Section 5. Concluding remarks are given in Section 6.

\section{Sampling Procedure and Estimating the Mean}

An extension of the AM method consists of two phases. In the first phase we draw a random sample of size $r^{2}$ from the population of interest, and then a sample of size only $r$ is selected from those $r^{2}$ units. In the second phase we repeat the first phase $m$ times such that $r m=n$, where $n$ is the final sample size. The procedure can be described as:

1. Select a random sample of size $r^{2}$ from the population of interest.

2. Arrange the $r^{2}$ units in ascending order and then divide the ordered sample into $r$ sets of $r$ units each.

3. Choose a sample of size $r$ for the actual analysis. This sample consists of the smallest ranked unit from the first set, the second smallest ranked unit from the second set, continuing until the largest ranked unit is selected from the last set. The chosen sample of size $r$ is then

$$
\begin{array}{cccc}
x_{\left(1: r^{2}\right)} & x_{\left(2: r^{2}\right)} & \cdots & x_{\left(r: r^{2}\right)} \\
x_{\left(r+1: r^{2}\right)} & x_{\left(r+2: r^{2}\right)} & \cdots & x_{\left(2 r: r^{2}\right)} \\
\vdots & \vdots & \cdots & \vdots \\
x_{\left.((r-1) r+1): r^{2}\right)} & x_{\left.((r-1) r+2): r^{2}\right)} & \cdots & x_{\left(r^{2}: r^{2}\right)} .
\end{array}
$$


4. Repeat steps 1 to $3 m$ times (cycles) until the desired sample size $n=m r$ is obtained. The final sample will be

$$
\begin{array}{cccc}
x_{\left(1: r^{2}\right) 1} & x_{\left(1: r^{2}\right) 2} & \cdots & x_{\left(1: r^{2}\right) m} \\
x_{\left((r+2): r^{2}\right) 1} & x_{\left((r+2): r^{2}\right) 2} & \cdots & x_{\left((r+2): r^{2}\right) m} \\
\vdots & \vdots & \cdots & \vdots \\
x_{\left(r^{2}: r^{2}\right) 1} & x_{\left(r^{2}: r^{2}\right) 2} & \cdots & x_{\left(r^{2}: r^{2}\right) m},
\end{array}
$$

where $x_{\left(i: r^{2}\right) j}$ represents the $i$-th order observation in the $j$-th column, $i=1, r+$ $2, \ldots, r^{2}, j=1,2, \ldots, m$, and each column represents the $r$ selected units obtained by repeating steps 1 to 3 . Note that units in the same row of the final sample are independent and identically distributed.

Using this sampling procedure the estimator of the population mean $\mu$ based on a sample of size $n=m r$ is given as

$$
\bar{X}_{\mathrm{AM}}=\frac{1}{m r} \sum_{i=1}^{r} \sum_{j=1}^{m} x_{\left(((i-1) r+i): r^{2}\right) j} .
$$

Its expected value is

$$
\mathrm{E}\left(\bar{X}_{\mathrm{AM}}\right)=\frac{1}{r} \sum_{i=1}^{r} \int_{\mathbb{R}} x_{\left(((i-1) r+i): r^{2}\right)} d F\left(x_{((i-1) r+i): r^{2}}\right),
$$

where the probability density function of $X_{(i: n)}$ is

$$
f\left(x_{(i: n)}\right)=\frac{n !}{(i-1) !(n-i) !}[F(x)]^{i-1}[1-F(x)]^{n-i} f(x) .
$$

Hence,

$\mathrm{E}\left(\bar{X}_{\mathrm{AM}}\right)=\frac{r^{2}}{r} \sum_{i=1}^{r} \int_{\mathbb{R}} x\left(\begin{array}{c}(r+1)(r-1) \\ (r+1)(i-1)\end{array}\right)[F(x)]^{(r+1)(i-1)}[1-F(x)]^{(r+1)(r-i)} d F(x)$.

Its variance is

$$
\begin{aligned}
& \operatorname{var}\left(\bar{X}_{\mathrm{AM}}\right)= \frac{1}{m r^{2}} \operatorname{var}\left(\sum_{i=1}^{r} X_{\left(((i-1) r+i): r^{2}\right)}\right) \\
&=\frac{1}{m r^{2}}\left(\sum_{i=1}^{r} \operatorname{var}\left(X_{\left(((i-1) r+i): r^{2}\right)}\right)\right. \\
&\left.\quad+2 \sum_{i=1}^{r-1} \sum_{j=i+1}^{r} \operatorname{cov}\left(X_{\left(((i-1) r+i): r^{2}\right)}, X_{\left(((j-1) r+j): r^{2}\right)}\right)\right) .
\end{aligned}
$$

For any distribution that is symmetric around zero, $X_{(i: n)}$ and $-X_{((n-i+1): n)}$, as also $\left(X_{(i: n)}, X_{(j: n)}\right)$ and $-\left(X_{((n-j+1): n)}, X_{((n-i+1): n)}\right)$ are identically distributed (Balakrishnan and Cohen, 1990). Thus, this estimator is unbiased for such distributions. Moreover, the relative efficiency of this estimator with respect to the traditional simple random sample (SRS) estimator is

$$
\frac{\operatorname{var}\left(\bar{X}_{\mathrm{SRS}}\right)}{\operatorname{var}\left(\bar{X}_{\mathrm{AM}}\right)}=\frac{\sigma^{2} r}{\sum_{i=1}^{r} \operatorname{var}\left(X_{\left(((i-1) r+i): r^{2}\right)}\right)+2 \sum_{i=1}^{r-1} \sum_{j=i+1}^{r} \operatorname{cov}\left(X_{\left(((i-1) r+i): r^{2}\right)}, X_{\left(((j-1) r+j): r^{2}\right)}\right)},
$$

where $\bar{X}_{\mathrm{SRS}}=\sum_{i=1}^{n} x_{i} / n$, and $\sigma^{2}$ denotes the variance of the population. 


\subsection{Results for the Standard Uniform Distribution}

Suppose that we select a random sample of size $n=m r$ from the standard uniform distribution $\mathrm{U}(0,1)$. It is easy to verify that

$$
\mathrm{E}\left(\bar{X}_{\mathrm{AM}}\right)=\frac{1}{r} \sum_{i=1}^{r} \frac{(i-1) r+i}{r^{2}+1}=\frac{1}{2}
$$

and

$$
\operatorname{var}\left(\bar{X}_{\mathrm{AM}}\right)=\frac{1}{12 n} \frac{2+r\left(r^{2}-2 r+5\right)}{2+3 r^{2}+r^{4}}
$$

Hence,

$$
\frac{\operatorname{var}\left(\bar{X}_{\mathrm{SRS}}\right)}{\operatorname{var}\left(\bar{X}_{\mathrm{AM}}\right)}=\frac{2+3 r^{2}+r^{4}}{2+r\left(r^{2}-2 r+5\right)} \geq 1
$$

Equality holds for $r=1$, which implies that the extension of the AM method gives a more efficient and an unbiased estimator of the uniform population mean compared to a SRS estimator. Clearly from Figure 1, the relative efficiency of the estimator increases as $r$ increases.

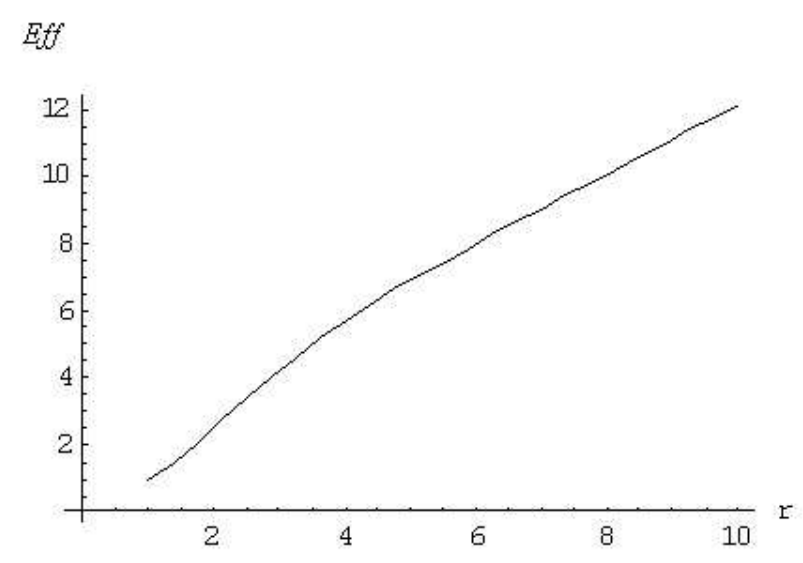

Figure 1: The relative efficiency of the estimator as a function of $r$.

\subsection{Results for Exponential Distribution}

Consider the case of selecting random samples from an exponential distribution with mean 1 . The mean and the variance of the proposed estimator will be

$$
\mathrm{E}\left(\bar{X}_{\mathrm{AM}}\right)=\frac{1}{r} \sum_{i=1}^{r} \sum_{k=1}^{(i-1) r+i} \frac{1}{r^{2}-k+1}
$$

and

$$
\operatorname{var}\left(\bar{X}_{\mathrm{AM}}\right)=\frac{1}{n r^{2}}\left(\sum_{i=1}^{r} \sum_{k=1}^{(i-1) r+i}\left(\frac{1}{r^{2}-k+1}\right)^{2}+2 \sum_{i=1}^{r-1} \sum_{j=i+1}^{r}\left(\frac{1}{r^{2}-j+1}\right)^{2}\right) .
$$




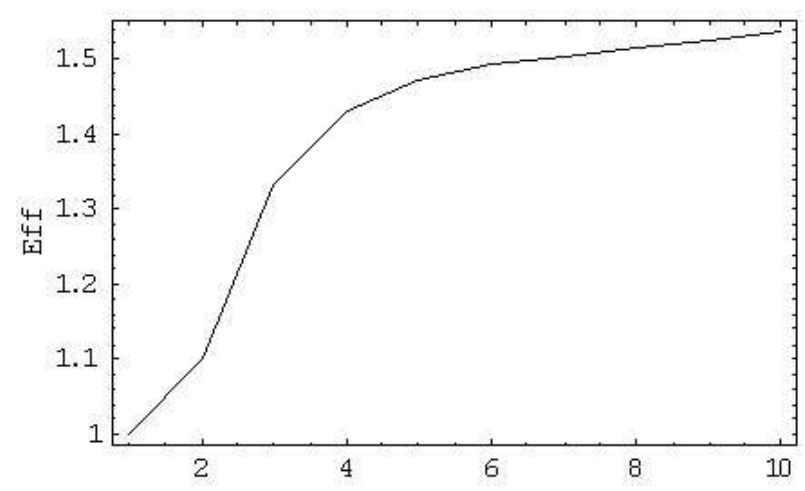

Figure 2: The efficiency of the estimator as a function of $r$ for the exponential distribution.

Since $\bar{X}_{\mathrm{AM}}$ is biased for skewed distributions, we consider $\operatorname{var}\left(\bar{X}_{\mathrm{SRS}}\right) / \mathrm{MSE}\left(\bar{X}_{\mathrm{AM}}\right)$, with mean squared error $\operatorname{MSE}\left(\bar{X}_{\mathrm{AM}}\right)=\operatorname{var}\left(\bar{X}_{\mathrm{AM}}\right)+\left(\mathrm{E}\left(\bar{X}_{\mathrm{AM}}\right)-1\right)^{2}$. From Figure 2 we clearly see that the efficiency of the estimator slowly increases as $r$ increases.

\section{Estimating Regression Coefficients}

The procedure consists of ordering the pairs $\left(x_{i}, y_{i}\right), i=1, \ldots, n$, by the magnitude of the $x_{i}$ 's and splitting the observations into some sets. This can be described as follows:

1. Select a random sample of size $r^{2}$ from the population.

2. Arrange the observations in ascending order with respect to the $x_{i}$ 's, i.e. $x_{\left(1: r^{2}\right)} \leq$ $x_{\left(2: r^{2}\right)} \leq \cdots \leq x_{\left(r^{2}: r^{2}\right)}$ and the associated $y_{[1]}, y_{[2]}, \ldots, y_{\left[r^{2}\right]}$ of the original data are taken.

3. Divide the $r^{2}$ ordered data into $r$ sets of $r$ observations each, such the sample can be rewritten as

$$
\begin{array}{cccc}
\left(x_{\left(1: r^{2}\right)}, y_{[1]}\right) & \left(x_{\left(2: r^{2}\right)}, y_{[2]}\right) & \cdots & \left(x_{\left(r: r^{2}\right)}, y_{[r]}\right) \\
\left(x_{\left((r+1): r^{2}\right)}, y_{[r+1]}\right) & \left(x_{\left((r+2): r^{2}\right)}, y_{[r+2]}\right) & \cdots & \left(x_{\left(2 r: r^{2}\right)}, y_{[2 r]}\right) \\
\vdots & \vdots & \cdots & \vdots \\
\left(x_{\left(((r-1) r+1): r^{2}\right)}, y_{[(r-1) r+1]}\right) & \left(x_{\left(((r-1) r+2): r^{2}\right)}, y_{[(r-1) r+2]}\right) & \cdots & \left(x_{((r-1) r+r): r^{2}}, y_{[(r-1) r+r]}\right)
\end{array}
$$

4. From the first set above select $\left(x_{\left(1: r^{2}\right)}, y_{[1]}\right)$, from the second set $\left(x_{\left((r+2): r^{2}\right)}, y_{[r+2]}\right)$, and continue till $\left(x_{\left(((r-1) r+r): r^{2}\right)}, y_{[(r-1) r+r]}\right)$ is taken from the $r$-th set.

5. Repeat steps 1 to $4 m$ times.

In order to illustrate the efficiency of this method for the bivariate case, we estimate the parameters of the simple linear regression model

$$
Y=\alpha+\beta X+\epsilon,
$$

where $Y$ is the response variable, the intercept $\alpha$ and the slope $\beta$ are unknown parameters, $X$ is the predictor variable and $\epsilon$ is a random error term assumed to have zero mean and variance $\sigma_{\epsilon}^{2}$. 
Let $\hat{\alpha}_{\mathrm{SRS}}$ and $\hat{\beta}_{\mathrm{SRS}}$ denote the least squares estimators of $\alpha$ and $\beta$, respectively, obtained considering a SRS, i.e.

$$
\hat{\alpha}_{\mathrm{SRS}}=\bar{y}_{\mathrm{SRS}}-\hat{\beta}_{\mathrm{SRS}} \bar{x}_{\mathrm{SRS}}, \quad \hat{\beta}_{\mathrm{SRS}}=\frac{\sum_{i=1}^{n}\left(x_{i}-\bar{x}_{\mathrm{SRS}}\right)\left(y_{i}-\bar{y}_{\mathrm{SRS}}\right)}{\sum_{i=1}^{n}\left(x_{i}-\bar{x}_{\mathrm{SRS}}\right)^{2}},
$$

where $\bar{x}_{\mathrm{SRS}}=\sum_{i=1}^{n} x_{i} / n$ and $\bar{y}_{\mathrm{SRS}}=\sum_{i=1}^{n} y_{i} / n$.

Similarly, the least squares estimators of $\alpha$ and $\beta$ obtained regarding the proposed method of a sample of size $n=r m$, respectively, are

$$
\hat{\alpha}_{\mathrm{AM}}=\frac{\sum_{i=1}^{\bar{y}_{\mathrm{AM}}-\hat{\beta}_{\mathrm{AM}} \bar{x}_{\mathrm{AM}}} \sum_{j=1}^{m}\left(x_{\left(((i-1) r+i): r^{2}\right) j}-\bar{x}_{\mathrm{AM}}\right)\left(y_{[(i-1) r+i] j}-\bar{y}_{\mathrm{AM}}\right)}{\sum_{i=1}^{r} \sum_{j=1}^{m}\left(x_{\left(((i-1) r+i): r^{2}\right) j}-\bar{x}_{\mathrm{AM}}\right)^{2}} .
$$

It can be shown that standard errors of these estimates are the square roots of

$$
\begin{gathered}
\operatorname{var}\left(\hat{\alpha}_{\mathrm{SRS}}\right)=\frac{\left(\frac{1}{n-2} \sum_{i=1}^{n}\left(y_{i}-\hat{y}_{i}\right)^{2}\right) \sum_{i=1}^{n} x_{i}^{2}}{n \sum_{i=1}^{n}\left(x_{i}-\bar{x}_{\mathrm{SRS}}\right)^{2}} \\
\operatorname{var}\left(\hat{\beta}_{\mathrm{SRS}}\right)=\frac{\frac{1}{n-2} \sum_{i=1}^{n}\left(y_{i}-\hat{y}_{i}\right)^{2}}{\sum_{i=1}^{n}\left(x_{i}-\bar{x}_{\mathrm{SRS}}\right)^{2}} \\
\left.\operatorname{var}\left(\hat{\alpha}_{\mathrm{AM}}\right)=\frac{1}{r m-2} \sum_{i=1}^{r} \sum_{j=1}^{m}\left(y_{[(i-1) r+i] j}-\hat{y}_{[(i-1) r+i] j}\right)^{2}\right)\left(\sum_{i=1}^{r} \sum_{j=1}^{m} x_{\left(((i-1) r+i): r^{2}\right) j}\right) \\
\operatorname{var}\left(\hat{\beta}_{\mathrm{AM}}\right)=\frac{r m \sum_{i=1}^{r} \sum_{j=1}^{m}\left(x_{\left(((i-1) r+i): r^{2}\right) j}-\bar{x}_{\mathrm{AM}}\right)^{2}}{\sum_{i=1}^{r} \sum_{j=1}^{m}\left(x_{\left(((i-1) r+i): r^{2}\right) j}-\bar{x}_{\mathrm{AM}}\right)^{2}} .
\end{gathered}
$$


Table 1: Data using SRS.

\begin{tabular}{rrrr}
\hline$(16000,679)$ & $(3500,427)$ & $(7400,374)$ & $(17000,803)$ \\
$(11900,482)$ & $(6000,373)$ & $(14800,640)$ & $(8400,442)$ \\
$(9200,492)$ & $(8100,432)$ & $(10900,500)$ & $(12700,549)$ \\
$(6400,405)$ & $(18500,925)$ & $(7500,440)$ & $(10000,428)$ \\
$(12900,610)$ & $(13700,635)$ & $(14600,622)$ & $(15600,727)$ \\
\hline
\end{tabular}

Table 2: Data using the AM procedure with $r=5$.

\begin{tabular}{rrrrrr}
\hline$m=1$ & $(6500,409)$ & $(11600,558)$ & $(12900,560)$ & $(15000,658)$ & $(16700,718)$ \\
2 & $(4500,399)$ & $(9900,489)$ & $(11100,485)$ & $(13200,554)$ & $(17700,858)$ \\
3 & $(3500,427)$ & $(7600,387)$ & $(9300,449)$ & $(13000,592)$ & $(15400,696)$ \\
4 & $(3900,417)$ & $(9900,439)$ & $(11400,516)$ & $(13700,553)$ & $(16200,907)$ \\
\hline
\end{tabular}

Table 3: Estimation Results.

\begin{tabular}{ccccc}
\hline & $\hat{\alpha}$ & $\operatorname{se}(\hat{\alpha})$ & $\hat{\beta}$ & $\operatorname{se}(\hat{\beta})$ \\
\hline AM & 238.989 & 36.379 & 0.0273 & 0.003 \\
SRS & 168.866 & 39.997 & 0.0338 & 0.003 \\
\hline
\end{tabular}

\section{Real Data Application}

The following example illustrates the extension of the AM method for the bivariate case. We have used the so-called car data from Graybill and Iyer (1994). Twenty cars were selected using the SRS and the AM procedure and shown in Tables 1 and 2, respectively. The response variable represents the first year maintenance costs and the explanatory variable represents the number of miles driven during the first year after purchase. Based on these two samples estimates of the simple linear regression parameters and their standard errors are calculated and given in Table 3.

Clearly, from Table 3 the proposed method has an overall smaller standard error than the traditional SRS. Moreover, Figure 3 shows the residuals and the predicted values for both estimation methods. It can be noted that both estimation methods give very similar values of the residuals and behave in a similar way.

\section{Simulation Study}

In order to compare the performance of the estimates of $\alpha$ and $\beta$ obtained using an extension of the AM method and a SRS, a simulation study is conducted. Define the relative efficiency of $\hat{\alpha}_{\mathrm{AM}}$ with respect to $\hat{\alpha}_{\mathrm{SRS}}$ as $\operatorname{Eff}(\hat{\alpha})=\operatorname{MSE}\left(\hat{\alpha}_{\mathrm{SRS}}\right) / \operatorname{MSE}\left(\hat{\alpha}_{\mathrm{AM}}\right)$, where $\operatorname{MSE}\left(\hat{\alpha}_{\mathrm{SRS}}\right)$ and $\operatorname{MSE}\left(\hat{\alpha}_{\mathrm{AM}}\right)$ are the mean squared error of $\hat{\alpha}_{\mathrm{SRS}}$ and $\hat{\alpha}_{\mathrm{AM}}$, respectively. Similarly we define the efficiency $\operatorname{Eff}(\hat{\beta})$. We simulate data for the model (1) with $\alpha=\beta=1$, i.e. $y_{i}=1+x_{i}+\epsilon_{i}$, where $x_{i} \sim N(0,1)$, and we consider different distributions for the error term:

1. Symmetric around zero with different scales, $\epsilon_{i} \sim N(0,1)$ and $\epsilon_{i} \sim N(0,4)$.

2. Non-normal skewed, i.e. $\epsilon_{i} \sim \operatorname{Beta}(2,9)$ and $\epsilon_{i} \sim \operatorname{Beta}(9,2)$. 

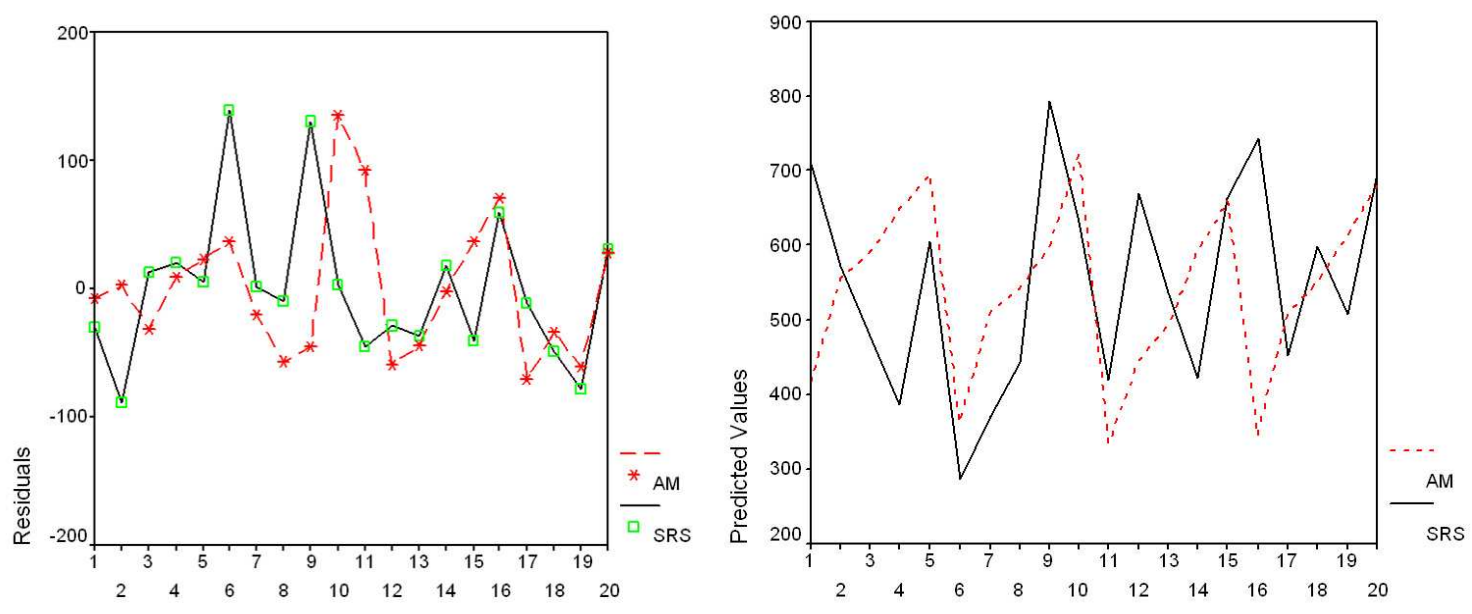

Figure 3: Residuals and predicted values for both estimation methods.

Note that the shape of $\operatorname{Beta}(2,9)$ is skewed to the right, while the shape of $\operatorname{Beta}(9,2)$ is skewed to the left.

Simulation results are provided in Tables 4 to 11 . Values of the biases are in Tables 4 , 6, 8, and 10, while those for the MSE's are in Tables 5, 7, 9, and 11. From these tables we conclude that the AM estimates behave very well for different types of error distributions. More specifically we see that the biases and mean square errors of the estimated parameters decreases as the sample size increases and the proposed AM estimates have smaller biases compared with the traditional SRS estimates. Calculating efficiencies shows that the proposed AM estimates are more efficient than the SRS estimates. We also see that the AM method is more efficient in estimating the slope than in estimating the intercept.

To estimate the mean of a symmetric distribution the analytical results show that the AM method often generates an unbiased estimator. As an example, the relative efficiencies in Figures 1 and 2 for the standard uniform and the exponential distribution show that the AM estimator is preferable over the traditional estimator based on a SRS.

\section{Concluding Remarks}

As a summary, simulation results demonstrate that the AM estimates are superior and often closer to the true parameter than the traditional estimates based on a SRS. For all situations used in the simulation study by considering different types of the error term distributions, the AM estimates are more efficient than the estimates based on a SRS. Consequently, the AM estimator can be recommended for estimating the mean of symmetric distributions and the parameters of regression model.

\section{Acknowledgements}

The authors thank the editor-in-chief and the referees for their valuable comments that improved the content and the style of the paper. Special thank to Professor LeAnna Stork for Language improvement. 
Table 4: Biases for $\epsilon_{i} \sim N(0,1)$.

\begin{tabular}{rrrrr}
\hline$n$ & $\operatorname{Bias}\left(\hat{\alpha}_{S R S}\right)$ & $\operatorname{Bias}\left(\hat{\alpha}_{A M}\right)$ & $\operatorname{Bias}\left(\hat{\beta}_{S R S}\right)$ & $\operatorname{Bias}\left(\hat{\beta}_{A M}\right)$ \\
\hline 10 & $1.417 \mathrm{E}-03$ & $1.305 \mathrm{E}-03$ & $1.079 \mathrm{E}-02$ & $-4.697 \mathrm{E}-03$ \\
30 & $-1.902 \mathrm{E}-04$ & $3.178 \mathrm{E}-03$ & $-3.702 \mathrm{E}-03$ & $-1.008 \mathrm{E}-03$ \\
50 & $-8.182 \mathrm{E}-04$ & $-1.421 \mathrm{E}-03$ & $1.139 \mathrm{E}-03$ & $1.460 \mathrm{E}-03$ \\
100 & $-1.990 \mathrm{E}-04$ & $2.866 \mathrm{E}-03$ & $-8.832 \mathrm{E}-04$ & $-4.523 \mathrm{E}-04$ \\
1000 & $3.974 \mathrm{E}-05$ & $-2.432 \mathrm{E}-04$ & $-1.121 \mathrm{E}-04$ & $5.595 \mathrm{E}-05$ \\
\hline
\end{tabular}

Table 5: Mean squared errors and efficiencies for $\epsilon_{i} \sim N(0,1)$.

\begin{tabular}{rrrrrrr}
\hline$n$ & $\operatorname{MSE}\left(\hat{\alpha}_{S R S}\right)$ & $\operatorname{MSE}\left(\hat{\alpha}_{A M}\right)$ & $\operatorname{Eff}(\hat{\alpha})$ & $\operatorname{MSE}\left(\hat{\beta}_{S R S}\right)$ & $\operatorname{MSE}\left(\hat{\beta}_{A M}\right)$ & $\operatorname{Eff}(\hat{\beta})$ \\
\hline 10 & $1.112 \mathrm{E}-01$ & $1.072 \mathrm{E}-01$ & 1.036 & $1.458 \mathrm{E}-01$ & $7.537 \mathrm{E}-02$ & 1.934 \\
30 & $3.446 \mathrm{E}-02$ & $3.346 \mathrm{E}-02$ & 1.030 & $3.650 \mathrm{E}-02$ & $1.889 \mathrm{E}-02$ & 1.931 \\
50 & $2.046 \mathrm{E}-02$ & $2.021 \mathrm{E}-02$ & 1.012 & $2.145 \mathrm{E}-02$ & $1.090 \mathrm{E}-02$ & 1.966 \\
100 & $1.039 \mathrm{E}-02$ & $9.912 \mathrm{E}-03$ & 1.048 & $1.043 \mathrm{E}-02$ & $5.642 \mathrm{E}-03$ & 1.849 \\
1000 & $1.013 \mathrm{E}-03$ & $9.982 \mathrm{E}-04$ & 1.015 & $9.958 \mathrm{E}-04$ & $6.566 \mathrm{E}-04$ & 1.516 \\
\hline
\end{tabular}

Table 6: Biases for $\epsilon_{i} \sim N(0,4)$.

\begin{tabular}{rrrrr}
\hline$n$ & $\operatorname{Bias}\left(\hat{\alpha}_{S R S}\right)$ & $\operatorname{Bias}\left(\hat{\alpha}_{A M}\right)$ & $\operatorname{Bias}\left(\hat{\beta}_{S R S}\right)$ & $\operatorname{Bias}\left(\hat{\beta}_{A M}\right)$ \\
\hline 10 & $-6.406 \mathrm{E}-04$ & $-7.121 \mathrm{E}-04$ & $1.483 \mathrm{E}-04$ & $-2.678 \mathrm{E}-03$ \\
30 & $1.895 \mathrm{E}-03$ & $5.011 \mathrm{E}-03$ & $-3.435 \mathrm{E}-03$ & $9.250 \mathrm{E}-04$ \\
50 & $2.990 \mathrm{E}-03$ & $1.650 \mathrm{E}-04$ & $1.133 \mathrm{E}-03$ & $-1.991 \mathrm{E}-04$ \\
100 & $-7.519 \mathrm{E}-05$ & $5.351 \mathrm{E}-04$ & $5.696 \mathrm{E}-04$ & $-8.138 \mathrm{E}-04$ \\
1000 & $1.871 \mathrm{E}-04$ & $1.672 \mathrm{E}-04$ & $5.859 \mathrm{E}-06$ & $7.236 \mathrm{E}-05$ \\
\hline
\end{tabular}

Table 7: Mean squared errors and efficiencies for $\epsilon_{i} \sim N(0,4)$.

\begin{tabular}{rrrrrrr}
\hline$n$ & $\mathrm{MSE}\left(\hat{\alpha}_{S R S}\right)$ & $\mathrm{MSE}\left(\hat{\alpha}_{A M}\right)$ & $\mathrm{Eff}(\hat{\alpha})$ & $\mathrm{MSE}\left(\hat{\beta}_{S R S}\right)$ & $\mathrm{MSE}\left(\hat{\beta}_{A M}\right)$ & $\operatorname{Eff}(\hat{\beta})$ \\
\hline 10 & $1.178 \mathrm{E}-01$ & $1.037 \mathrm{E}-01$ & 1.136 & $1.429 \mathrm{E}-01$ & $7.906 \mathrm{E}-02$ & 1.808 \\
30 & $3.480 \mathrm{E}-02$ & $3.306 \mathrm{E}-02$ & 1.052 & $3.739 \mathrm{E}-02$ & $1.841 \mathrm{E}-02$ & 2.030 \\
50 & $2.045 \mathrm{E}-02$ & $2.015 \mathrm{E}-02$ & 1.014 & $2.128 \mathrm{E}-02$ & $1.110 \mathrm{E}-02$ & 1.916 \\
100 & $9.966 \mathrm{E}-03$ & $9.853 \mathrm{E}-03$ & 1.011 & $1.034 \mathrm{E}-02$ & $5.675 \mathrm{E}-03$ & 1.822 \\
1000 & $1.010 \mathrm{E}-03$ & $9.813 \mathrm{E}-04$ & 1.030 & $1.003 \mathrm{E}-03$ & $5.749 \mathrm{E}-04$ & 1.745 \\
\hline
\end{tabular}

Table 8: Biases for $\epsilon_{i} \sim \operatorname{Beta}(2,9)$.

\begin{tabular}{rrrrr}
\hline$n$ & $\operatorname{Bias}\left(\hat{\alpha}_{S R S}\right)$ & $\operatorname{Bias}\left(\hat{\alpha}_{A M}\right)$ & $\operatorname{Bias}\left(\hat{\beta}_{S R S}\right)$ & $\operatorname{Bias}\left(\hat{\beta}_{A M}\right)$ \\
\hline 10 & $1.819 \mathrm{E}-01$ & $1.812 \mathrm{E}-01$ & $-2.217 \mathrm{E}-03$ & $1.359 \mathrm{E}-04$ \\
30 & $1.813 \mathrm{E}-01$ & $1.818 \mathrm{E}-01$ & $3.476 \mathrm{E}-04$ & $6.835 \mathrm{E}-06$ \\
50 & $1.817 \mathrm{E}-01$ & $1.817 \mathrm{E}-01$ & $5.878 \mathrm{E}-05$ & $-5.395 \mathrm{E}-04$ \\
100 & $1.816 \mathrm{E}-01$ & $1.816 \mathrm{E}-01$ & $8.692 \mathrm{E}-04$ & $8.324 \mathrm{E}-04$ \\
1000 & $1.818 \mathrm{E}-01$ & $1.818 \mathrm{E}-01$ & $-3.904 \mathrm{E}-04$ & $-3.202 \mathrm{E}-04$ \\
\hline
\end{tabular}

Table 9: Mean squared errors and efficiencies for $\epsilon_{i} \sim \operatorname{Beta}(2,9)$.

\begin{tabular}{rrrrrrr}
\hline$n$ & $\mathrm{MSE}\left(\hat{\alpha}_{S R S}\right)$ & $\mathrm{MSE}\left(\hat{\alpha}_{A M}\right)$ & $\mathrm{Eff}(\hat{\alpha})$ & $\mathrm{MSE}\left(\hat{\beta}_{S R S}\right)$ & $\mathrm{MSE}\left(\hat{\beta}_{A M}\right)$ & $\mathrm{Eff}(\hat{\beta})$ \\
\hline 10 & $3.892 \mathrm{E}-02$ & $3.677 \mathrm{E}-02$ & 1.058 & $1.539 \mathrm{E}-01$ & $7.893 \mathrm{E}-02$ & 1.950 \\
30 & $3.456 \mathrm{E}-02$ & $3.418 \mathrm{E}-02$ & 1.011 & $3.836 \mathrm{E}-02$ & $1.850 \mathrm{E}-02$ & 2.073 \\
50 & $3.399 \mathrm{E}-02$ & $3.372 \mathrm{E}-02$ & 1.008 & $2.148 \mathrm{E}-02$ & $1.132 \mathrm{E}-02$ & 1.897 \\
100 & $3.346 \mathrm{E}-02$ & $3.335 \mathrm{E}-02$ & 1.003 & $1.050 \mathrm{E}-02$ & $5.960 \mathrm{E}-03$ & 1.762 \\
1000 & $3.313 \mathrm{E}-02$ & $3.309 \mathrm{E}-02$ & 1.001 & $9.918 \mathrm{E}-04$ & $6.613 \mathrm{E}-04$ & 1.499 \\
\hline
\end{tabular}


Table 10: Biases for $\epsilon_{i} \sim \operatorname{Beta}(9,2)$.

\begin{tabular}{rrrrr}
\hline$n$ & $\operatorname{Bias}\left(\hat{\alpha}_{S R S}\right)$ & $\operatorname{Bias}\left(\hat{\alpha}_{A M}\right)$ & $\operatorname{Bias}\left(\hat{\beta}_{S R S}\right)$ & $\operatorname{Bias}\left(\hat{\beta}_{A M}\right)$ \\
\hline 10 & $8.196 \mathrm{E}-01$ & $8.141 \mathrm{E}-01$ & $5.001 \mathrm{E}-03$ & $-1.907 \mathrm{E}-03$ \\
30 & $8.193 \mathrm{E}-01$ & $8.202 \mathrm{E}-01$ & $-1.731 \mathrm{E}-03$ & $-2.375 \mathrm{E}-03$ \\
50 & $8.188 \mathrm{E}-01$ & $8.164 \mathrm{E}-01$ & $-5.748 \mathrm{E}-04$ & $2.385 \mathrm{E}-03$ \\
100 & $8.170 \mathrm{E}-01$ & $8.185 \mathrm{E}-01$ & $1.500 \mathrm{E}-03$ & $-5.876 \mathrm{E}-04$ \\
1000 & $8.181 \mathrm{E}-01$ & $8.182 \mathrm{E}-01$ & $5.146 \mathrm{E}-05$ & $-1.082 \mathrm{E}-04$ \\
\hline
\end{tabular}

Table 11: Mean squared errors and efficiencies for $\epsilon_{i} \sim \operatorname{Beta}(9,2)$.

\begin{tabular}{rrrrrrr}
\hline$n$ & $\mathrm{MSE}\left(\hat{\alpha}_{S R S}\right)$ & $\mathrm{MSE}\left(\hat{\alpha}_{A M}\right)$ & $\mathrm{Eff}(\hat{\alpha})$ & $\mathrm{MSE}\left(\hat{\beta}_{S R S}\right)$ & $\mathrm{MSE}\left(\hat{\beta}_{A M}\right)$ & $\operatorname{Eff}(\hat{\beta})$ \\
\hline 10 & $7.697 \mathrm{E}-01$ & $7.258 \mathrm{E}-01$ & 1.060 & $1.536 \mathrm{E}-01$ & $7.935 \mathrm{E}-02$ & 1.936 \\
30 & $6.965 \mathrm{E}-01$ & $6.854 \mathrm{E}-01$ & 1.016 & $3.678 \mathrm{E}-02$ & $1.891 \mathrm{E}-02$ & 1.944 \\
50 & $6.853 \mathrm{E}-01$ & $6.740 \mathrm{E}-01$ & 1.016 & $2.172 \mathrm{E}-02$ & $1.108 \mathrm{E}-02$ & 1.960 \\
100 & $6.748 \mathrm{E}-01$ & $6.740 \mathrm{E}-01$ & 1.001 & $1.050 \mathrm{E}-02$ & $5.956 \mathrm{E}-03$ & 1.763 \\
1000 & $6.700 \mathrm{E}-01$ & $6.700 \mathrm{E}-01$ & 1.000 & $1.000 \mathrm{E}-03$ & $6.477 \mathrm{E}-04$ & 1.545 \\
\hline
\end{tabular}

\section{References}

Al-Haj Ebrahem, M., and Al-Nasser, A. D. (2005). Estimating the slope of simple linear regression in the presence of outliers. Journal of Modern Applied Statistical Methods, 4, 509-513.

Al-Nasser, A. D., and Al-Haj Ebrahem, M. (2005). A new nonparametric method for estimating the slope of measurement error model in the presence of outliers. Pakistan Journal of Statistics, 21, 265-274.

Balakrishnan, N., and Cohen, A. (1990). Order Statistics and Inference: Estimation Methods. UK: Academic Press Inc.

Deming, E. W. (1953). On a probability mechanism to attain an economic balance between the resultant error of response and the bias of nonresponse. Journal of the American Statistical Association, 48, 743-772.

Graybill, F. A., and Iyer, H. K. (1994). Regression Analysis: Concepts and Applications. California: Duxbury Press.

Authors' Address:

Amjad D. Al-Nasser and Mohammed Al-Haj Ebrahem

Department of Statistics

Faculty of Science

Yarmouk University

Irbid - Jordan

E-mail: amjadn@yu.edu.jo and m_hassanb@hotmail.com 